\title{
Cathodic protection of structures in seawater using solar panels
}

\author{
Boris Borisovich Chernov ${ }^{1, *}$, Van Mung $\mathrm{Vu}^{1,2}$, Anac Maskharovich Nugmanov ${ }^{1}$, Lyudmila Yuryevna Firsova ${ }^{1}$ \\ ${ }^{1}$ Department of chemistry and ecology, Maritime State University named after adm. G.I. Nevelskoy, 690059 Vladivostok, Russia \\ ${ }^{2}$ Marine engineering department, Vietnam Maritime University, 180000 Haiphong, Vietnam
}

\begin{abstract}
It is well known that the cathodic protection of structures in seawater is accompanied by the formation of calcareous deposits on them. In current study, we consider the physicochemical modelling of the formation of the deposit composition against cathode current density in seawater. The reliability of the model representations is confirmed by direct experiments. The work also studied the protective properties of the deposits with a different composition for low-alloy steels in natural sea water. It has been shown that the deposits of pure $\mathrm{Mg}(\mathrm{OH})_{2}$ and the deposits of $\mathrm{CaCO}_{3}+\mathrm{Mg}(\mathrm{OH})_{2}$ had better protective ability against corrosion than the deposits of pure $\mathrm{CaCO}_{3}$. However, the deposits of $\mathrm{Mg}(\mathrm{OH})_{2}$ dissolved faster than the deposits of $\mathrm{CaCO}_{3}$ and $\mathrm{CaCO}_{3}+\mathrm{Mg}(\mathrm{OH})_{2}$. Theoretical concepts and experiments on the laws governing the formation of the deposits and their protective properties are in complete agreement with each other. This allows to use the obtained patterns in the cathodic protection of structures in sea water using solar panels, forming standard deviations with predetermined protective properties in the daytime.
\end{abstract}

\section{Introduction}

Seawater is a very aggressive corrosive medium for various metal structures, depending on the nature of the metal, the chemical and microbiological composition of seawater and its physicochemical characteristics. The accumulated centuries-old experience of experimental study of corrosion losses and numerous theoretical works still do not allow understanding the subtleties of the process of metal corrosion in natural sea water [1-3]. Despite this, most researchers believe that the most effective protection of low-alloy steels in seawater is cathodic protection, the essence of which lies in imposing an external cathode current on the protected product.

Cathodic protection of steel in seawater is accompanied by the formation on the metal surface of calcareous deposits, which have a high protective ability against corrosion $[4,5]$. Elucidation of the mechanism for the deposition of the deposits and their protective properties is of particular importance when used in cathodic protection as a source of protective current for solar panels. The peculiarity of this kind of protection is that in the daytime, in the presence of a protective current, it is necessary to form a salt coating of such a quality that, in the dark of the day, when there is no protective current, would provide effective protection of the metal against destruction due to corrosion.

To control the quality of such deposits, a deep understanding of the physicochemical processes that accompany the formation and dissolution of the coatings of deposits is required, which is the aim of this work.

\section{Theoretical and experimental study of calcareous deposit formation}

\subsection{Theoretical study}

In the process of electrolysis of aqueous solutions of electrolytes, including sea water, alkalization of the electrolyte occurs in the cathode region due to the reactions of discharge of oxygen dissolved in water and the release of hydrogen:

$$
\begin{gathered}
\mathrm{O}_{2}+4 e^{-}+2 \mathrm{H}_{2} \mathrm{O} \rightarrow 4 \mathrm{OH}^{-}, \\
2 \mathrm{H}_{2} \mathrm{O}+2 e^{-} \rightarrow 2 \mathrm{OH}^{-}+\mathrm{H}_{2} \uparrow .
\end{gathered}
$$

At certain cathode current densities and with the presence of hardness salts in the electrolyte, it is possible to achieve and exceed values of the solubility product of calcium carbonates and magnesium hydroxides, which leads to their crystallization on the polarized surface of the electrodes. The increase in $\mathrm{pH}$ at the surface of the cathode under the action of the cathode current is buffered with bicarbonate ions due to homogeneous carbonate equilibrium

$$
\mathrm{OH}^{-}+\mathrm{HCO}_{3}^{-} \leftrightarrow \mathrm{CO}_{3}^{2-}+\mathrm{H}_{2} \mathrm{O} .
$$

The determination of the quantitative model of the kinetics of the deposit formation is the main factor for finding the optimal compositions of the deposits and cathodic protection modes.

In theoretical studies of the deposit formation, methods of numerical simulation of mass transfer, diffusion, migration, and convection $[6,7]$ are widely used, although they are cumbersome and do not allow

\footnotetext{
* Corresponding author: chernov@msun.ru
} 
obtaining the required dependencies explicitly, and therefore can carry imagine hidden inaccuracies.

In the theoretical study of the crystallization of hydroxides and carbonates, a model of diffusion mass transfer with galvanostatic electrolysis can be successfully used, which allows to quantitatively estimate the partial crystallization rates of calcium carbonate and magnesium hydroxide in aqueous electrolytes of seawater type depending on the density of external cathode current.

With an excess of extraneous electrolyte, transfer under the action of an electric field is not required, and the distribution of the concentrations of hydroxide, hydrocarbonate and carbonate ions $\left(C_{1}, C_{2}\right.$ and $C_{3}$, respectively) in the diffusion layer is determined by their diffusion transport taking into account the homogeneous carbonate equilibrium (3). Determining the distribution of concentrations of hydroxide ions, bicarbonate ions, and carbonate ions in the diffusion layer with possible co-crystallization of calcium carbonate and magnesium hydroxide is reduced to the solution of the system [8]

$$
\left.\begin{array}{c}
D_{2} \frac{\partial C_{2}}{\partial x}+D_{3} \frac{\partial C_{3}}{\partial x}=\frac{i_{1}}{F} \\
D_{1} \frac{\partial C_{1}}{\partial x}+D_{3} \frac{\partial C_{2}}{\partial x}=\frac{-i}{F}+\frac{i_{1}}{F}+\frac{i_{2}}{F} \\
C_{1} C_{2}=K C_{3}
\end{array}\right\}
$$

where $D_{1}, D_{2}, D_{3}$, respectively, the diffusion coefficients of hydroxide ions, hydrocarbonate and carbonate in the diffusion layer; $K$ - apparent homogeneous carbonate equilibrium constant; $i$ - the external current density; $i_{l}$, $i_{2}$ - the crystallization current of calcium carbonate and magnesium hydroxide, respectively; $F$ - the Faraday number.

The first equation of system (4) describes the balance of fluxes of carbonate and hydrocarbonate ions, the second, the fluxes of hydroxide and carbonate ions, and the third takes into account the presence of homogeneous equilibrium between these ions.

It is difficult to obtain a simple analytical solution of the system (4), therefore, the Matlab application package was used. In calculations reference values were known $\left(D_{1}=5 \times 10^{-9} \mathrm{~m}^{2} / \mathrm{s}, D_{2}=D_{3}=1.4 \times 10^{-9} \mathrm{~m}^{2} / \mathrm{s} ; C_{1}^{o}\right.$ $=2.3 \times 10^{-5} \mathrm{M}, C_{2}^{o}=2 \times 10^{-3} \mathrm{M}, C_{3}^{o}=1.25 \times 10^{-4} \mathrm{M} ; K=$ $\left.1.3 \times 10^{-5} \mathrm{~mol} / \mathrm{l}\right)[9-11]$ with activity coefficients for magnesium ions - 0.4 ; calcium - 0,2 ; hydroxide ions 0.7 ; carbonate ions - $0.02, \delta=4 \times 10^{-5} \mathrm{~m}$ [12].

The results of the solutions calculated in the program Matlab and system (4) for the crystallization currents of $\mathrm{Mg}(\mathrm{OH})_{2}$ and $\mathrm{CaCO}_{3}$, depending on the external current density, are presented in Fig.1.

From Fig. 1 the crystallization current of $\mathrm{CaCO}_{3}$ increases at current densities up to $1.5 \mathrm{~A} / \mathrm{m}^{2}$. At higher values, the crystallization current of $\mathrm{CaCO}_{3}$ remains constant at the level of $0.017 \mathrm{~A} / \mathrm{m}^{2}$, which corresponds to the limiting current of diffusion over bicarbonate ions. The crystallization current of $\mathrm{Mg}(\mathrm{OH})_{2}$ is close to zero if the external current density is up to $1.0 \mathrm{~A} / \mathrm{m}^{2}$. At higher current densities, the crystallization of $\mathrm{Mg}(\mathrm{OH})_{2}$ increases exponentially.

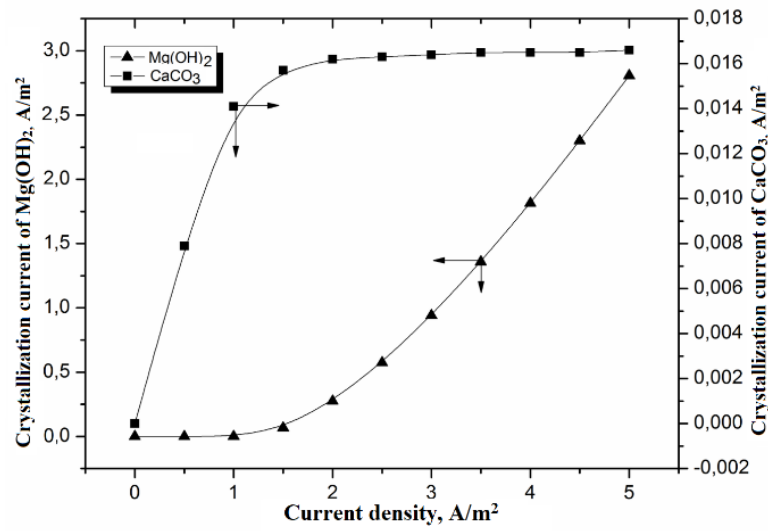

Fig. 1. Crystallization currents of $\mathrm{Mg}(\mathrm{OH})_{2}$ and $\mathrm{CaCO}_{3}$ against external current density.

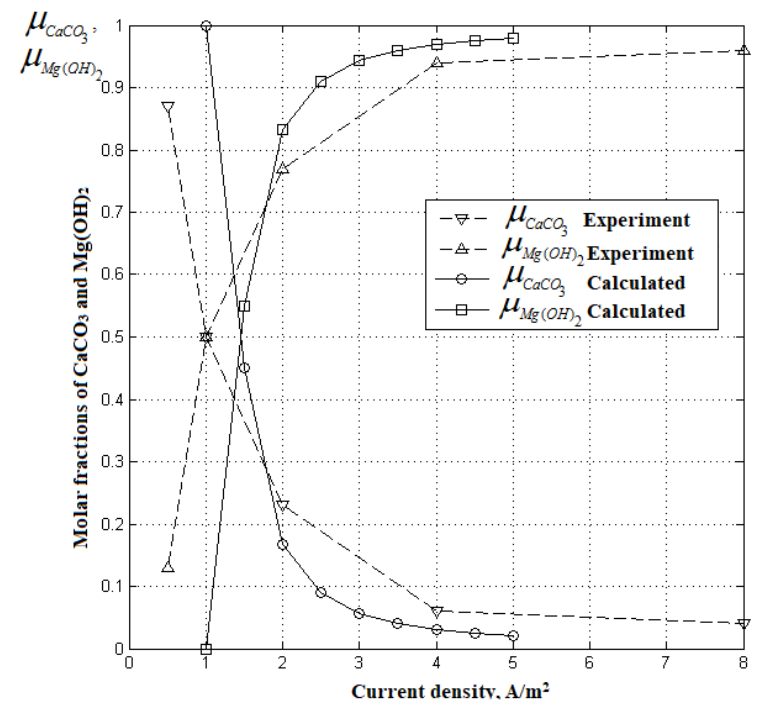

Fig. 2. Calculated and experimental ratios of the molar fractions of $\mathrm{CaCO}_{3}$ and $\mathrm{Mg}(\mathrm{OH})_{2}$ in deposits

\subsection{Experimental study}

Table 1. The content of $\mathrm{Ca}$ and $\mathrm{Mg}$ according to the results of the elemental analysis of the deposits in atomic percent (a.p \%) and molar fractions (m.f ppm) depending on the current density $(i)$

\begin{tabular}{|c|c|c|c|c|}
\hline \multirow{2}{*}{$i, \mathrm{~A} / \mathrm{M}^{2}$} & \multicolumn{2}{|c|}{$C a$} & $M g$ & \multicolumn{2}{c|}{$C a$} & $M g$ \\
\cline { 2 - 5 } & \multicolumn{2}{|c|}{ a.p, \% } & \multicolumn{2}{c|}{ m.f, ppm } \\
\hline 0.5 & 31.9 & 4.77 & 0.87 & 0.13 \\
\hline 1.0 & 17.8 & 17.6 & 0.50 & 0.50 \\
\hline 2.0 & 7.66 & 25.7 & 0.23 & 0.77 \\
\hline 4.0 & 2.27 & 37.2 & 0.06 & 0.94 \\
\hline 8.0 & 1.41 & 38.8 & 0.04 & 0.96 \\
\hline
\end{tabular}

The experimental ratio of the molar fractions of $\mathrm{CaCO}_{3}$ and $\mathrm{Mg}(\mathrm{OH})_{2}$ in the deposits prepared in laboratory in seawater at different current densities was calculated using elemental analysis of sediment samples from the cathode surface, which was carried out on an electron probe (WDS/EDS) JXA-8100 combined microanalyzer 
(Japan). The results of the analyses are presented in Table 1.

With cathodic polarization of steel in sea water, the mole fraction of $\mathrm{CaCO}_{3}$ in the deposits decreases with increasing external current density, and the mole fraction of $\mathrm{Mg}(\mathrm{OH})_{2}$ in the deposits increases. Statistical processing of the results of experiments using non-linear estimation results with the correlation coefficient $\mathrm{R}=$ 0.9985 leads to ex-potential dependencies:

$$
\begin{aligned}
& \mu_{\mathrm{CaCO}_{3}}=0.036+1.348 e^{-i}, \\
& \mu_{\mathrm{Mg}(\mathrm{OH})_{2}}=0.964-1.348 e^{-i} .
\end{aligned}
$$

From the experimental results presented in Fig. 2, it can be seen that, at currents of $1.0 \div 1.5 \mathrm{~A} / \mathrm{m}^{2}$, equal mole fractions of $\mathrm{CaCO}_{3}$ and $\mathrm{Mg}(\mathrm{OH})_{2}$ are formed in the cathode deposit. The experimental results and theoretical calculations in the proposed model are quite consistent.

Calculated data and experimental results on precipitation composition showed that coatings formed at current densities of $1.0 \div 1.5 \mathrm{~A} / \mathrm{m}^{2}$ have the best protective properties when $\mathrm{CaCO}_{3}$ and $\mathrm{Mg}(\mathrm{OH})_{2}$ form at the same rate (Fig. 2)

\section{Protective properties of the deposits in seawater}

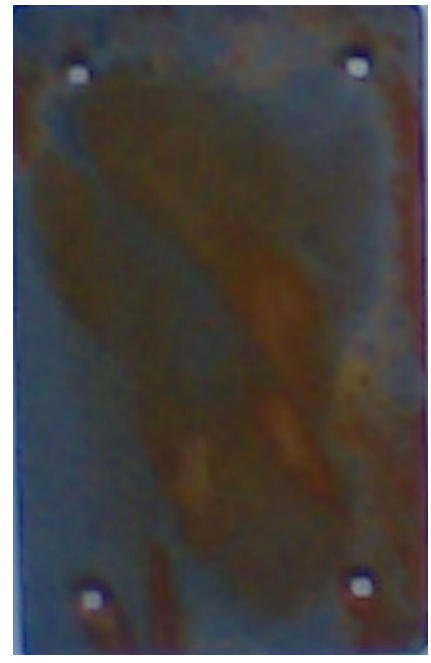

a) $\mathrm{CaCO}_{3}$ (after 2 hours)

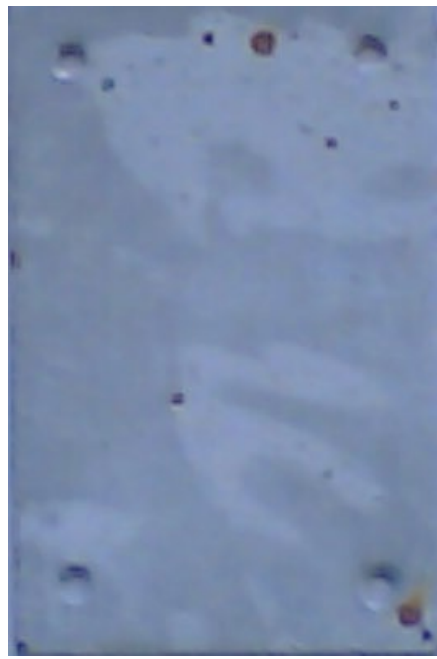

b) $\mathrm{Mg}(\mathrm{OH})_{2}$ (after 7 hours)

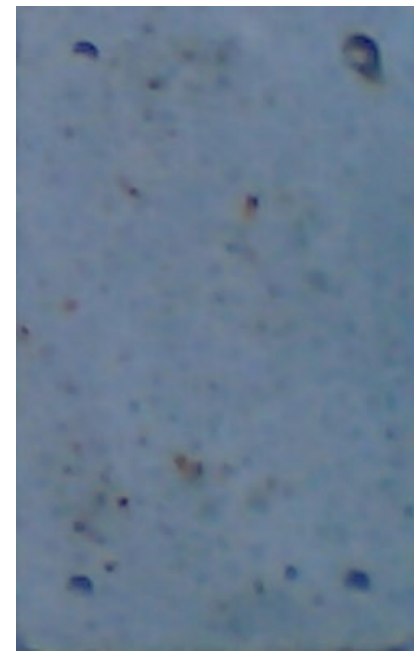

c) $\mathrm{CaCO}_{3}+\mathrm{Mg}(\mathrm{OH})_{2}$ (after 12 hours)

Fig. 3. The protective properties of the deposits in seawater formed under a current density $\mathrm{i}=1.0 \mathrm{~A} / \mathrm{m}^{2}$ on the surface of steel St3hp within 48 hours.

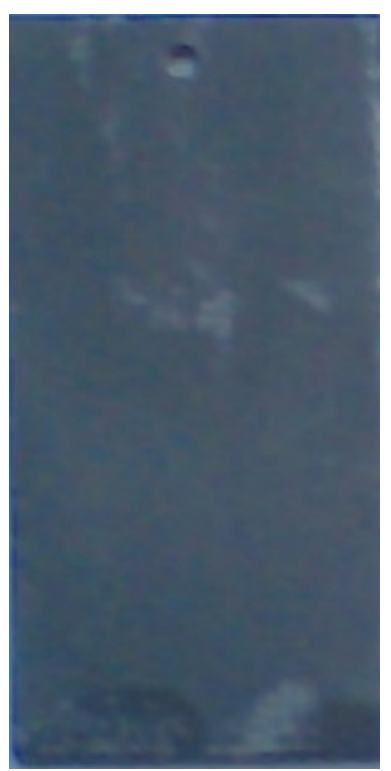

$\mathrm{CaCO}_{3}$

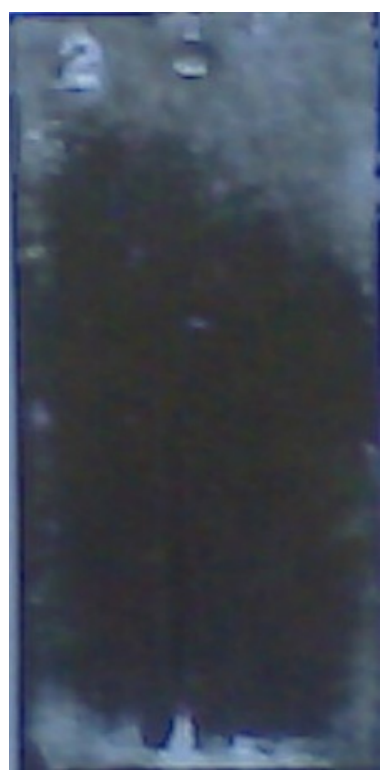

$\mathrm{Mg}(\mathrm{OH})_{2}$

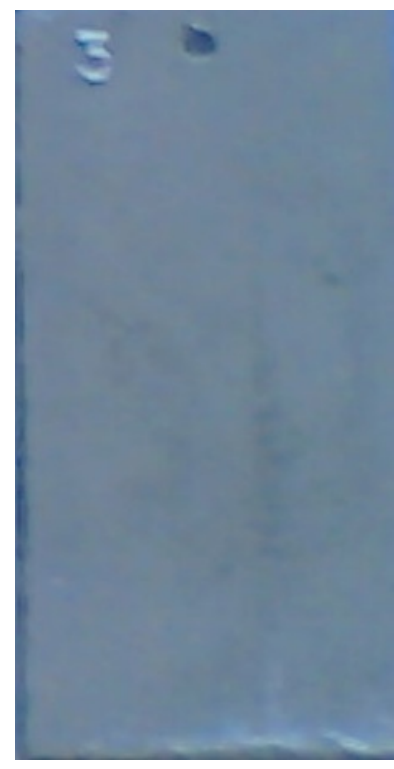

$\mathrm{CaCO}_{3}+\mathrm{Mg}(\mathrm{OH})_{2}$

Fig. 4. Stability in the seawater of the deposits formed under the current density $i=1.0 \mathrm{~A} / \mathrm{m}^{2}$ on the surface of stainless steel 12X18H10T within 48 hours. 
The persistence of the deposits formed with a current density of $1.0 \mathrm{~A} / \mathrm{m}^{2}$ in model solutions and seawater for 48 hours with a current density of $1.0 \mathrm{~A} / \mathrm{m}^{2}$ was determined by prolonged holding of the samples in natural seawater. As can be seen from Fig. 3, steel St3hp under a coating of $\mathrm{CaCO}_{3}$ (coating thickness of $12 \mu \mathrm{m}$ ) explored in sea water begins to rust quickly after 2-3 hours. The coating is practically insoluble and at the same time does not have noticeable protective properties. At the same time, corrosion spreads over the entire surface (Fig. 3a).

Under the coating of $\mathrm{Mg}(\mathrm{OH})_{2}$ with a thickness of 7 $\mu \mathrm{m}$, St3hp does not corrode in seawater for at least 7 hours. After this time, point sources of rust appear (Fig. $3 b)$. At the same time, the coating dissolves. In the case of cathode deposits formed from seawater, when they are kept in seawater after 12 hours, pinpoint corrosion begins to appear (Fig. 3c).

Fig. 4 shows samples of stainless steel $12 \mathrm{X} 18 \mathrm{H} 10 \mathrm{~T}$ with the deposits, formed within 2 days with a current density of $1.0 \mathrm{~A} / \mathrm{m}^{2}$ in model solutions, after keeping them in seawater for 5 days. Samples coated with $\mathrm{CaCO}_{3}$ and $\mathrm{CaCO}_{3}+\mathrm{Mg}(\mathrm{OH})_{2}$ remained almost unchanged, and the sample coated with $\mathrm{Mg}(\mathrm{OH})_{2}$ almost completely lost its coating.

\section{Conclusions}

The consistency of the theoretical and experimental results allows us to make a conclusion about the correctness of ideas on the mass crystallization of lowsoluble compounds in sea water on the surface of metals with their cathodic polarization. The results obtained can be used in the practice of cathodic protection using solar panels, forming the deposits of the pre-set protective properties in the daytime.

When using cathodic protection using solar panels on a real object, the problem of the occurrence of reverse current at night is encountered. Such a current can lead to the destruction of the formed deposits in the daytime and reduce their adhesion to the protected objects without reducing the characteristics of insoluble anodes. In real protection systems, the fight against this problem comes down to turning on a diode circuit or using traditional circuit breakers.

With the modern development of electronics and remote control of controller signals using GSM, the use of solar panels for cathodic protection of offshore facilities, the remote stationary sources of electricity is particularly attractive.

\section{References}

1. B.B. Chernov, I.A. Chaves, A.M. Nugmanov, R.E. Melchers. Mater. Conf. "Corrosion \& Prevention 2017'. ACA (2017)

2. B.B. Chernov, T.B. Pustovskikh, G.M. Chertkova, Pro. of Met. (Eng. trans.of Zaschita Metallov) 25(4) (1990)
3. B.B. Chernov, I.A. Chaves, A.M. Nugmanov, R.E. Melchers, Corrosion 74(12) (2018)

4. R. A. Humble. Corrosion 4 (1948)

5. C. Deslouis, P. Falaras, O. Gil, M. Jeannin, et al. Electrochimica Acta. 51 (2006)

6. Wen Sun, Guichang Liu, Lida Wang, Yu Li, Electrochimica Acta. 78 (2012)

7. J.F. Yan, T.V. Nguyen, R.E. White, R.B. Griffin, J. of the Elec. So. 140 (1993)

8. B.B. Chernov, T.B. Pustovskikh, Pro. of Met. (Eng. trans. of Zaschita Metallov) 25(3) (1990)

9. N. I. Popov, K. N. Fedorov, and V. M. Orlov, Sea Water (Nauka, Moscow, 1979) [in Russian]

10. D. Dobos, Electrochemical constants (Mir, Moscow, 1978) [in Russian]

11. R. Horn, Sea water (Mir, Moscow, 1972) [in Russian]

12. B.B. Chernov, Pro. of Met. (Eng. trans. of Zaschita Metallov) 21 (1985) 